\title{
A APLICAÇÃo do CONTROLE DE CONVENCIONALIDADE PELO JUIZ BRASILEIRO: O CASO DO CRIME DE DESACATO
}

\author{
Saulo de Medeiros Torres ${ }^{1}$ \\ Keity Mara Ferreira de Souza e Saboya ${ }^{2}$
}

Recebido em: 23/10/2017

Aprovado em: 11/12/2017

\begin{abstract}
RESUMO
A teoria do controle de convencionalidade vem trazendo importantes debates no direito brasileiro. Uma das discussões diz respeito a adequação do crime de desacato com a Convenção Americana de Direitos Humanos. A Corte Interamericana de Direitos Humanos já se pronunciou sobre a incompatibilidade do tipo penal e a liberdade de expressão prevista no Pacto de San José da Costa Rica. No caso do Brasil, nossa legislação penal contempla tal ilícito, surgindo a importância de saber como o Poder Judiciário brasileiro irá atuar ao ter que julgar casos concretos onde se suscite a inconvencionalidade do delito.
\end{abstract}

Palavras-Chave: Desacato. Controle de Convencionalidade. Poder Judiciário.

\section{INTRODUÇÃO}

Diversas convenções internacionais de Direitos Humanos estão incorporadas ao ordenamento jurídico brasileiro. Uma delas é a Convenção Americana de Direitos Humanos (ou Pacto de San José da Costa Rica), que trouxe impactos na concretização interna e internacional dos direitos humanos.

Verificando-se o fenômeno da pluralidade de ordens jurídicas e da possibilidade de fontes de distintas origens poderem incidir para resolução de um determinado caso concreto, é

\footnotetext{
${ }^{1}$ Mestrando em Direito pela Universidade Federal do Rio Grande do Norte (UFRN). Especialista em Direito Constitucional e Tributário pela Universidade Potiguar (UnP).

${ }^{2}$ Doutora em Direito Penal pela Universidade do Estado do Rio de Janeiro (UERJ). Mestre em Direito pela UFRN. Especialista em Direito Processual Civil e Penal pela Universidade Potiguar (UnP). Professora Adjunta do Departamento de Direito Público da UFRN. Membro permanente do corpo docente do Programa de PósGraduação em Direito da UFRN. Juíza de Direito do Estado do Rio Grande do Norte.
} 
relevante a existência de um mecanismo que possibilite a compatibilização entre normas domésticas e normas internacionais.

Através do mecanismo do controle de convencionalidade essa adequação torna-se possível. Tal instrumento vem sendo realizado perante órgãos judiciais internacionais, como a Corte Interamericana de Direitos Humanos e paulatinamente os juízes brasileiros estão observando em suas decisões a necessidade do exame desse controle.

A problemática escolhida nesse trabalho foi analisar a discussão em torno da descriminalização do tipo penal de desacato em razão de seu eventual desrespeito ao Pacto de San José da Costa Rica. Tal estudo torna-se importante de ser realizado em razão da incidência normativa do mencionado tratado no plano doméstico, enaltecendo-se que o Brasil reconheceu a jurisdição da Corte Interamericana de Direitos Humanos, permitindo com isso que esse tribunal condene o país por eventuais violações de direitos previstos no tratado internacional. A partir do momento que os juízes brasileiros comecem a utilizar do controle de convencionalidade, fica diminuída a possibilidade de tal condenação.

O presente artigo possui por objetivo geral verificar se o crime de desacato viola a Convenção Americana de Direitos Humanos e seus objetivos específicos são analisar a aplicação da teoria do controle de convencionalidade das leis no REsp 1.640.084 do STJ, bem como esclarecer os fundamentos para que o juiz brasileiro realize o controle de convencionalidade.

A metodologia utilizada foi a pesquisa bibliográfica e o estudo de caso. O primeiro capítulo do estudo faz um estudo geral acerca do controle de convencionalidade, esclarecendo seu significado, sua evolução histórica, as normas que podem ser objeto e parâmetro, seus efeitos e uma breve classificação dos tipos de controle. No segundo capítulo realiza-se uma abordagem panorâmica do tipo penal de desacato e suas implicações para a liberdade de expressão.

No último capítulo é feita a análise do julgamento do REsp 1.640.084 do STJ e como a teoria do controle de convencionalidade foi aplicada no mesmo. Com esse caso, portanto, já se torna importante entender os desdobramentos que a hierarquia dos tratados de direitos humanos possui no Brasil e onde o cenário para o uso dessa teoria só aumenta. 
Antes de abordar as características gerais acerca do controle de convencionalidade, é relevante realizar uma contextualização do fenômeno da pluralidade de ordens jurídicas e suas respectivas consequências para as relações jurídicas que estão sendo vivenciadas no Século XXI.

Como reflexo da globalização, percebe-se que atualmente o direito interno não convive mais isolado, pois numa sociedade internacional onde cada vez os Estados e outros cooperam entre si, o ordenamento jurídico interno terá que interagir com a ordem internacional (GOMES; GONÇALVES, 2016).

Diante deste cenário, é que se torna importante compreender a pluralidade de ordens jurídicas. O Brasil vem ratificando diversos instrumentos internacionais sobre os assuntos mais diversos, o que vem gerando uma expansão do Direito Internacional. As normas internacionais estão versando sobre distintos assuntos, que também recebem algum tipo de tratamento no âmbito interno (ex: Direitos Humanos) e com isso surge a dificuldade do relacionamento entre esses normas internas e internacionais (RAMOS, 2012).

Segundo André de Carvalho Ramos, a pluralidade de ordens jurídicas pode ser entendida como a "coexistência de normas e decisões de diferentes matrizes com ambição de regência do mesmo espaço social, gerando uma série de consequências relacionadas à convergência ou divergência de sentidos entre as normas e decisões de origens distintas" (RAMOS, 2012, p. 500).

Com o controle de convencionalidade, essa relação problemática entre normas internas e internacionais começa a ganhar um mecanismo para a sua resolução. Como será visto adiante, o controle de convencionalidade possibilita que os tratados internacionais de direitos humanos sirvam como parâmetro de controle da produção normativa interna brasileira (CHAVES; SOUSA, 2016).

\subsection{Significado do controle de convencionalidade}

Buscando encontrar um conceito preliminar do que vem a ser controle de convencionalidade, utiliza-se a doutrina de Valério Mazzuoli sobre o tema. Segundo o autor, o mecanismo que consiste em verificar a adequação das normas produzidas internamente com os tratados internacionais de direitos humanos que estejam vigorando no país, pode ser chamado de controle de convencionalidade (MAZZUOLI, 2011).

Complementando as lições acima expostas, o controle de convencionalidade significa a avaliação dos atos das autoridades estatais, levando em consideração o Direito Internacional 
dos Direitos Humanos, enunciado em tratados e convenções internacionais (RAMIREZ; SANCHÉS, 2014). Deste modo, o seu objetivo é analisar a conformidade dos preceitos jurídicos internos de um país com o teor das disposições normativas previstas em tratados internacionais de direitos humanos por ele ratificado e que encontrem-se em vigor (CHAVES; SOUSA, 2016).

Surge assim, a denominada teoria do duplo controle. Para que as normas internas sejam consideradas válidas eles precisam passar por dois testes: a) $O$ controle de constitucionalidade; b) O controle de convencionalidade (RAMOS, 2012). Como consequência, aparece a chamada dupla compatibilidade vertical material: As normas internas devem estar em conformidade tanto com a Constituição Federal e também com os tratados internacionais de direitos humanos devidamente incorporados ao ordenamento jurídico brasileiro (MARTINS; MOREIRA, 2011).

Aponta-se que a origem da expressão controle de convencionalidade é datada do ano de 1975, de uma decisão proveniente do Conselho Constitucional Francês, onde se examinava a questão da possibilidade de interrupção voluntária da gestação e a eventual violação do direito à vida assegurado pela Convenção Europeia de Direitos Humanos (CHAVES; SOUSA, 2016). A corte francesa entendeu que era incompetente para efetuar um controle preventivo de convencionalidade das leis, pois sua atuação versava tão somente para se pronunciar acerca do controle de constitucionalidade propriamente dito (MAZZUOLI, 2011).

Assim, o julgamento acima mencionado reconheceu a existência de duas formas diferentes de efetuar o controle das normas: o controle de constitucionalidade e o de convencionalidade. Na decisão, o Conselho Constitucional usou como fundamentação da sua decisão dois dispositivos da Constituição da França de 1958: O art. 55, que consagra a supremacia dos tratados internacionais sobre as leis e o Art. 61, que trata da competência do Conselho Constitucional para realização do controle de constitucionalidade. A conclusão que o órgão chegou foi que esses dois artigos estabelecem controles distintos e desse modo, o Conselho não poderia analisar o princípio enunciado no Art. 55, levando em consideração a previsão do Art. 61 (CHAVES; SOUSA, 2016).

2.2 Desenvolvimento da teoria do controle de convencionalidade na jurisprudência da corte interamericana de direitos humanos

Conforme comentado anteriormente, a origem da expressão controle de convencionalidade é oriunda da França. Apesar disso, o desenvolvimento do controle de 
convencionalidade contou com a atuação decisiva de um órgão internacional: A Corte Interamericana de Direitos Humanos.

Será brevemente abordado no presente tópico, a evolução da jurisprudência do tribunal sobre a teoria em apreço. Não se pretende realizar uma análise exaustiva de toda a jurisprudência do órgão judicial do sistema interamericano, mas apontar os casos mais representativos que levou ao desenvolvimento da teoria do controle de convencionalidade no âmbito regional.

Aponta-se como principal antecedente do controle de convencionalidade no sistema interamericano, o voto do juiz Sérgio Garcia Ramirez, proferido no caso Myrna Mack Chang no ano de 2003 (GARCÍA, 2016). Nesse voto, Garcia Ramirez enaltece a inviabilidade do Estado se apresentar de forma separada perante o Direito Internacional, justificando na separação dos poderes uma limitação para implementação dos deveres internacionalmente contraídos (TORELY, 2016).

Pela relevância que o voto possui, transcreve-se o trecho onde o magistrado menciona expressamente o controle de convencionalidade:

\begin{abstract}
Não é possível separar internacionalmente o Estado, sujeitando perante a Corte somente determinados órgãos, conferindo a estes a representação do Estado no julgamento - sem que essa representação reflita sobre o Estado em seu conjunto - e subtraindo outros deste regime convencional de responsabilidade, deixando suas performaces fora do controle de convencionalidade que traz consigo a jurisdição da Corte Internacional (CORTE INTERAMERICANA DE DIREITOS HUMANOS. Caso Myrna Mack Chang vs. Guatemala, voto concorrente do Juiz Sergio García Ramírez, $§ 27$, tradução nossa). ${ }^{3}$
\end{abstract}

Para Marcelo Torely, a construção jurisprudencial do controle de convencionalidade pela Corte Interamericana pode ser dividida em 05 etapas. A primeira etapa seria encontrada nos votos individuais do Juiz Sérgio Garcia Ramirez, no caso Myrna Mack Chang acima citado e no caso Vargas Areco de 26 de setembro de 2006 (TORELY, 2016).

Analisando o voto de Garcia Ramirez no julgamento do Caso Vargas Areco, percebese um esboço de uma conceituação do controle de convencionalidade, pois realça que a Corte Interamericana de Direitos Humanos, tem a seu cargo o controle de convencionalidade que baseia-se na comparação entre o ato realizado e as disposições da Convenção Americana de Direitos Humanos (CORTE INTERAMERICANA DE DIREITOS HUMANOS. Vargas Areco vs. Paraguai. Voto Concorrente do Juiz Sérgio Garcia Ramirez, § $06^{\circ}$ ).

\footnotetext{
${ }^{3}$ No original: "No es posible seccionar internacionalmente al Estado, obligar ante la Corte sólo a uno o algunos de sus órganos, entregar a éstos la representación del Estado en el juicio --sin que esa representación repercuta sobre el Estado en su conjunto-- y sustraer a otros de este régimen convencional de responsabilidad, dejando sus actuaciones fuera del "control de convencionalidad" que trae consigo la jurisdicción de la Corte internacional".
} 
Ainda representando essa primeira etapa do controle de convencionalidade nos votos individuais do Juiz Sergio Garcia Ramirez, cabe mencionar o Caso Tibi de 2004, onde realiza um comparativo entre o controle de convencionalidade e o controle de constitucionalidade:

\begin{abstract}
A Corte Interamericana, entretanto, avalia os atos que chegam ao seu conhecimento em relação às normas, princípios e valores dos tratados que instituem sua competência contenciosa. Dito de outro modo, se os tribunais constitucionais realizam o controle de constitucionalidade, o tribunal internacional de direitos humanos resolve acerca da "convencionalidade" de tais atos (CORTE INTERAMERICANA DE DIREITOS HUMANOS. Caso Tibi vs. Equador, voto concorrente do Juiz Sergio García Ramírez, $\S 3^{\circ}$, tradução nossa). ${ }^{4}$
\end{abstract}

A segunda etapa da evolução traz o dever dos juízes nacionais realizarem o controle de convencionalidade, considerando as disposições da Convenção Americana de Direitos Humanos e como as mesmas são interpretadas pela Corte Interamericana de Direitos Humanos (TORELY, 2016). O caso que representa essa fase é o julgamento realizado em Almonacid Arellano, onde a composição plenária do tribunal utilizou pela primeira vez a expressão controle de convencionalidade (HITTERS, 2009).

A sentença do Caso Almonacid Arellano foi proferida em 26 de setembro de 2006, considerando que:

\begin{abstract}
Mas quando um Estado ratifica um tratado internacional como a Convenção Americana, seus juízes, como parte do aparato estatal, também estão submetidos a ela, o que os obriga a velar para que os efeitos das disposições da Convenção não se vejam diminuídos pela aplicação de leis contrárias a seu objeto e a seu fim e que, desde o início, carecem de efeitos jurídicos. Em outras palavras, o Poder Judiciário deve exercer uma espécie de "controle de convencionalidade" entre as normas jurídicas internas aplicadas a casos concretos e a Convenção Americana sobre Direitos Humanos. Nesta tarefa, o Poder Judiciário deve levar em conta não apenas o tratado, mas também a interpretação que a Corte Interamericana, intérprete última da Convenção Americana, fez do mesmo.
\end{abstract}

Deste julgamento podem ser extraídos as noções essenciais do controle de convencionalidade: a) há um dever do poder judiciário em cumprir as normas internacionais que o Estado incorporou internamente e, portanto, tornou-se parte do ordenamento jurídico; b) as regras contrárias ao Pacto de San José da Costa Rica não podem ser aplicadas a nível interno, uma vez que as regras que violam obrigações internacionais configuram um ilícito internacional, configurando a possibilidade de responsabilização estatal; c) para realizar o controle de convencionalidade, o juiz deve levar em conta a jurisprudência da Corte Interamericanda de Direitos Humanos (ROJAS, 2013).

\footnotetext{
${ }^{4}$ No original: "La Corte Interamericana, por su parte, analiza los actos que llegan a su conocimiento en relación con normas, principios y valores de los tratados en los que funda su competencia contenciosa. Dicho de outra manera, si los tribunales constitucionales controlan la 'constitucionalidad', el tribunal internacional de derechos humanos resuelve acerca de la 'convencionalidad' de esos actos".
} 
A terceira etapa do desenvolvimento jurisprudencial interamericano do controle de convencionalidade, diz respeito a realização do controle de convencionalidade de ofício por parte dos tribunais domésticos (TORELY, 2016). O julgamento que simboliza esse período histórico, é o Caso Trabajadores Cesados del Congreso, de 26 de novembro de 2006.

Neste momento, a Corte considera que:

[...] os órgãos do Poder Judiciário devem realizar não somente um controle de constitucionalidade, senão também, de convencionalidade ex officio entre as normas internas e a Convenção Americana, evidentemente no marco de suas respectivas competências e dos preceitos processuais adequados (CORTE INTERAMERICANA DE DIREITOS HUMANOS. Caso Trabajadores Cesados del Congreso (Aguado Alfaro y otros) Vs. Perú, $§ 128$, tradução nossa). ${ }^{5}$

As mudanças apontadas entre as posições em Almonacid Arellano e Trabajadores Cesados, dizem respeito ao fato de que na primeira sentença a Corte se pronunciou de forma abrangente sobre o controle de convencionalidade, já na segunda mencionou especificamente o dever do Poder Judiciário de realizar para além do controle de constitucionalidade, o controle de convencionalidade (BAZAN, 2011).

O quarto estágio é caracterizado pelo reconhecimento de uma eficácia vinculante equivalente à da Constituição, onde se reconheceu que o sistema regional de proteção aos direitos humanos como uma ordem semelhante ao sistema constitucional (TORELY, 2016). A Corte Interamericana passou a ressaltar que o controle de convencionalidade incumbe a qualquer juiz ou tribunal que materialmente exerça atribuições judiciais (ROJAS, 2013), ocasionando uma ampliação da teoria e reconheceu que inclusive os Tribunais Constitucionais deveriam desempenhar o controle de convencionalidade (TORELY, 2016).

Dois julgamentos são importantes de serem apontados para ilustrar a etapa acima caraterizada, o caso Boyce de 2007 e o caso Cabrera Garcia de 2010. No primeiro julgamento, a Corte considerou que "A análise do CJCP não deveria ter se limitado a avaliar se a LDCP era inconstitucional. Em vez disso, a questão deveria ter girado em torno de saber se a lei era também 'convencional"” (CORTE INTERAMERICANA DE DIREITOS HUMANOS. Caso Boyce y outros vs. Barbados, $\S 78$, tradução nossa). ${ }^{6}$ Percebe-se do trecho transcrito que esse entendimento da margem ao desenvolvimento da teoria do duplo controle já mencionada nesse estudo.

\footnotetext{
${ }^{5}$ No original: "En otras palabras, los órganos del Poder Judicial deben ejercer no sólo un control de constitucionalidad, sino también 'de convencionalidad'ex officio entre las normas internas y la Convención Americana, evidentemente en el marco de sus respectivas competencias y de las regulaciones procesales correspondientes".

${ }^{6}$ No original: "El análisis del CJCP no debería haberse limitado a evaluar si la LDCP era inconstitucional. Más bien, la cuestión debería haber girado en torno a si la ley también era 'convencional"”.
} 
O caso Cabrera Garcia assume importância, pois foi nele que se fez alusão categórica a expressão bloco de convencionalidade (GONÇALVES, 2013). Nas palavras da Corte:

\begin{abstract}
É formado deste modo um autêntico "bloco de convencionalidade" como parâmetro para exercer o "controle difuso de convencionalidade". Os juízes nacionais devem considerar esse bloco, o que significa, por sua vez, uma atualização continua da jurisprudência da Corte IDH e proporciona uma "viva interação" entre as jurisdições nacionais e a interamericana, com a finalidade de estabelecer estandardes em nossa região para a proteção efetiva dos direitos humanos (CORTE INTERAMERICANA DE DIREITOS HUMANOS. Caso Cabrera García y Montiel Flores Vs. México, § 50 , tradução nossa). ${ }^{7}$
\end{abstract}

Nesse mesmo julgamento, o tribunal corrobora a opinião de que todo juiz deve exercer o controle de convencionalidade (ROJAS, 2013) e reconhece que também os "órgãos vinculados à administração da justiça em todos os níveis são obrigados a exercer de ofício um 'controle de convencionalidade' entre as normas nacionais e da Convenção Americana" (CORTE INTERAMERICANA DE DIREITOS HUMANOS. Caso Cabrera García y Montiel Flores Vs. México, $\S 225$, tradução nossa). ${ }^{8}$

A quinta e última fase considerada por Torely se caracteriza pela declaração da falta de efeitos de certas disposições legais e pela revisão de decisões das instituições democraticamente eleitas, revelando um caráter contramajoritário (TORELY, 2016). Os dois casos relevantes desse momento são o julgamento Gomes Lund e o julgamento Gelman.

No caso Gomes Lund a Corte considerou que a lei de anistia brasileira não possuía efeitos jurídicos válidos (CORTE INTERAMERICANA DE DIREITOS HUMANOS. Caso Gomes Lund e outros vs. Brasil, §325.3), diferentemente do que tinha estabelecido em julgamentos anteriores onde o tribunal não tinha se pronunciado expressamente sobre esse ausência de efeitos jurídicos, determinado apenas sua adequação (TORELY, 2016).

Já no caso Gelman, houve o reconhecimento de que qualquer autoridade pública pode efetuar o controle de convencionalidade, não se limitando apenas aos órgãos judiciais (ROJAS, 2013). Então, além do aspecto contramajoritário anteriormente exposto, o Caso Gelman ampliou as autoridades que podem realizar o controle de convencionalidade:

\footnotetext{
${ }^{7}$ No original: "Se forma de esta manera un auténtico 'bloque de convencionalidad como parámetro para ejercer el "control difuso de convencionalidad". Los jueces nacionales deben atender a este 'bloque', lo que implica, por parte de ellos, una permanente actualización de la jurisprudencia de la Corte IDH y propicia una 'viva interacción' entre las jurisdicciones nacionales y la interamericana, con la finalidad última de establecer estándares en nuestra región para la protección efectiva de los derechos humanos".

${ }^{8}$ No original: "Los jueces y órganos vinculados a la administración de justicia en todos los niveles están en la obligación de ejercer ex officio un 'control de convencionalidad' entre las normas internas y la Convención Americana, evidentemente en el marco de sus respectivas competencias y de las regulaciones procesales correspondientes".
} 


\begin{abstract}
A legitimação democrática de determinados fatos ou atos numa sociedade está limitada pelas normas e obrigações internacionais de proteção dos direitos humanos reconhecidos em tratados como a Convenção Americana, de modo que a existência de um verdadeiro regime democrático está determinada por suas características tanto formais como substantivas, motivo pelo qual particularmente em casos de graves violações às normas do Direito Internacional, a proteção dos direitos humanos constitui um limite intransponível à regra de maiorias, isto é, à esfera do "suscetível de ser decidido" por parte das maiorias em instâncias democráticas, nas quais também deve primar um "controle de convencionalidade" (par. 193 supra), que é função e tarefa de qualquer autoridade pública e não apenas do Poder Judiciário.
\end{abstract}

\title{
2.3 Fundamentos para a realização do controle de convencionalidade
}

Para avançar no estudo do controle de convencionalidade, é relevante apontar de onde provém sua obrigatoriedade, ou seja, seu fundamento (ROJAS, 2013). Pode-se dizer que são dois os fundamentos gerais para a realização do citado mecanismo: a) o cumprimento de boafé das obrigações internacionalmente contraídas; b) a impossibilidade de alegar as normas internas para a inobservância dos compromissos internacionais, conforme estabelece o Art. 27 da Convenção de Viena sobre Direito dos Tratados de $1969^{9}$ (SAGUÉS, 2010; GARCIA, 2016).

Buscando encontrar um fundamento em instrumentos mais específicos, Cláudio Nash Rojas considera que controle de convencionalidade baseia-se numa interpretação conjunta dos Arts. $1.1^{10}, 2^{11}$ e $29^{12}$ da Convenção Americana de Direitos Humanos (ROJAS, 2013). Desse modo, cabe aos Estados a obrigação de adotar todas as medidas para garantir o respeito, a defesa e a promoção dos direitos humanos. Se configura, assim, uma obrigação de garantia, que impõe ao aparato estatal organizar sua estrutura para permitir o gozo e o uso dos direitos e liberdades consagrados na Convenção Americana (ROJAS, 2013).

\footnotetext{
9 "Uma parte não pode invocar as disposições de seu direito interno para justificar o inadimplemento de um tratado".

10 "Os Estados Partes nesta Convenção comprometem-se a respeitar os direitos e liberdades nela reconhecidos e a garantir seu livre e pleno exercício a toda pessoa que esteja sujeita à sua jurisdição, sem discriminação alguma por motivo de raça, cor, sexo, idioma, religião, opiniões políticas ou de qualquer outra natureza, origem nacional ou social, posição econômica, nascimento ou qualquer outra condição social".

11 "Se o exercício dos direitos e liberdades mencionados no artigo 1 ainda não estiver garantido por disposições legislativas ou de outra natureza, os Estados Partes comprometem-se a adotar, de acordo com as suas normas constitucionais e com as disposições desta Convenção, as medidas legislativas ou de outra natureza que forem necessárias para tornar efetivos tais direitos e liberdades".

12 "Nenhuma disposição desta Convenção pode ser interpretada no sentido de: a) permitir a qualquer dos Estados Partes, grupo ou pessoa, suprimir o gozo e exercício dos direitos e liberdades reconhecidos na Convenção ou limitá-los em maior medida do que a nela prevista; b)limitar o gozo e exercício de qualquer direito ou liberdade que possam ser reconhecidos de acordo com as leis de qualquer dos Estados Partes ou de acordo com outra convenção em que seja parte um dos referidos Estados; c) excluir outros direitos e garantias que são inerentes ao ser humano ou que decorrem da forma democrática representativa de governo; e d) excluir ou limitar o efeito que possam produzir a Declaração Americana dos Direitos e Deveres do Homem e outros atos internacionais da mesma natureza".
} 
Um princípio do direito internacional que pode ser utilizado como fundamentação para a realização do controle de convencionalidade é o pacta sunt servanda, positivado no Art. 26 da Convenção de Viena sobre Direito dos Tratados de $1969^{13}$ e que significa o dever que possuem os Estados de implementar os tratados que sejam partes (ROJAS, 2013).

O controle de convencionalidade pode encontrar também seu fundamento no direito constitucional interno, nos casos onde a Constituição tenha consagrado expressamente a supremacia hierárquica dos tratados internacionais sobre as normas infraconstitucionais, ou então os tribunais nacionais tenham reconhecido jurisprudencialmente tal superioridade (CAVALLO, 2013).

No caso do Brasil, o único dispositivo constitucional expresso em atribuir uma hierarquia diferenciada aos tratados de direitos humanos é o $\S 3^{\circ}$ do Art. $5^{\circ}$, incluído pela EC 45/2004 ${ }^{14}$. Em relação a jurisprudência, o Supremo Tribunal Federal no julgamento do RE 466.343 entendeu, por maioria de votos, que os tratados de direitos humanos são superiores a legislação infraconstitucional, podendo ter dois níveis hierárquicos a depender do rito de incorporação dos tratados: a) hierarquia supralegal para aqueles incorporados pelo rito ordinário e b) hierarquia constitucional para aqueles que observarem o procedimento especial estabelecido no $\S 3^{\circ}$ do Art. $5^{\circ}$ da Constituição Federal de 1988.

Nesse estudo, adota-se o entendimento que independentemente da forma de incorporação do tratado de direitos humanos, realizando-se uma interpretação sistemática e teleológica da Constituição, os mesmos possuem natureza de norma constitucional (PIOVESAN, 2013). Mas mesmo que se adote a posicionamento do STF, percebe-se que ele garante uma superioridade dos tratados de direitos humanos, frente as normas infraconstitucionais, seja através da hierarquia supralegal ou através da hierarquia constitucional.

Decorre de ambos os fundamentos expostos, tanto no plano interno como no plano internacional, que as autoridades brasileiras possuem o dever de realizar o controle de convencionalidade,

\subsection{Tipos de controle de convencionalidade}

\footnotetext{
13 "Todo tratado em vigor obriga as partes e deve ser cumprido por elas de boa fé".

14 "Os tratados e convenções internacionais sobre direitos humanos que forem aprovados, em cada Casa do Congresso Nacional, em dois turnos, por três quintos dos votos dos respectivos membros, serão equivalentes às emendas constitucionais".
} 
Pretende-se apresentar suscintamente, uma classificação básica dos modelos de controle de convencionalidade que podem ser utilizados. Uma primeira classificação é aquela que divide o controle em externo ou interno.

O controle externo de convencionalidade é realizado pela Corte Interamericana de Direitos Humanos com o objetivo de analisar a compatibilidade entre atos internos e normas internacionais, examinando casos que são submetidos ao seu conhecimento e aos quais aplica regras de acordo com sua competência material (RAMIREZ, 2011). Já o controle interno de convencionalidade, se desenvolve em sede nacional, sendo efetuado pelos juízes (podendo incluir outras autoridades públicas) domésticos e consiste no dever de verificar a adequação das normas jurídicas internas que são aplicadas em casos concretos com a Convenção Americana de Direitos Humanos e outros tratados internacionais relevantes para a proteção da dignidade humana e os padrões interpretativos que a Corte Interamericana de Direitos Humanos foi desenvolvendo na sua jurisprudência (BAZAN, 2015).

Outra classificação que pode ser apontada é aquela que é feita entre controle difuso e controle concentrado. $\mathrm{O}$ controle difuso de convencionalidade é aquele que pode ser realizado por qualquer juiz ou tribunal (MAZZUOLI, 2011), já o controle concentrado de convencionalidade, sua configuração irá depender do critério classificatório adotado, pois se for levado em consideração o plano interno, o mesmo será efetivado perante o STF, tendo como parâmetro apenas os tratados internacionais de direitos humanos incorporados pelo rito estabelecido no $\S 3^{\circ}$, utilizando os instrumentos processuais da ADI, ADC, ADO e ADPF (MAZZUOLI, 2011). Se considerar o plano internacional, o controle concentrado de convencionalidade será desempenhado pela Corte Interamericana de Direitos Humanos, no exercício da sua jurisdição contenciosa ao resolver os casos que são submetidos a sua consideração (MAC-GREGOR, 2011).

Também é possível ocorrer o controle preventivo de convencionalidade, quando as comissões do Poder Legislativo que analisam um projeto de lei o rejeitem por entender que o mesmo pode violar alguma convenção internacional de direitos humanos que o Brasil faça parte. Outra possibilidade de atuação preventiva no controle de convencionalidade, é a viabilidade do uso do veto por parte do Presidente da República, por considerar que o projeto de lei é inconvencional por estar em desacordo com o interesse público (MARTINS; MOREIRA, 2011). O controle repressivo é viável de ocorrer tanto na via difusa como na via concentrada.

2.5 Normas que podem ser objeto do controle de convencionalidade 
No presente tópico analisa-se qual é o material normativo que pode ser controlado perante controle de convencionalidade. Aqui pode-se verificar um problema, a depender do plano aonde o controle seja realizado, pois será possível a ocorrência de entendimentos divergentes entre o controle externo e o interno.

Em relação ao controle externo, há o entendimento de que qualquer norma jurídica interna (leis, decretos, resoluções, regulamentos etc) estão sujeitas a esse controle, podendo ser incluídas inclusive as normas constitucionais (SAGUÉS, 2010; BAZAN, 2011). A Corte Interamericana já teve a oportunidade de se pronunciar sobre esse tema, no caso conhecido como "A Última Tentação de Cristo", entendendo que: "a responsabilidade internacional do Estado pode ser gerada por atos ou omissões de qualquer poder ou órgão, independentemente de sua hierarquia, que violem a Convenção Americana". O Tribunal considerou portanto que uma norma da Constituição do Chile que permitia a censura prévia, violava o Pacto de San José da Costa Rica.

Diante desse posicionamento, surge o problema da realização do controle interno de convencionalidade, levando em consideração o contexto brasileiro. O problema é que a jurisprudência do STF não admite a físcalização das normas elaboradas pelo Poder Constituinte Originário (RAMOS, 2014), disso resulta um impasse: e se a norma da Constituição for inconvencional? Caso o Tribunal mantenha sua jurisprudência, ele não efetuaria o controle interno de convencionalidade e mesmo que no Brasil haja a possibilidade de outros tribunais exercerem o controle de convencionalidade, o entendimento do STF sobre a impossibilidade da fiscalização das normas constitucionais originárias, vem sendo aplicado pelos demais órgãos judiciais brasileiros.

Já as Emendas Constitucionais (que possuem hierarquia constitucional), em tese poderiam ser objeto do controle de convencionalidade. Mas o problema que se configuraria nessa hipótese é que conforme mencionado anteriormente, o STF só considera que os tratados de direitos humanos possuem hierarquia constitucional se os mesmos forem incorporados pelo procedimento estabelecido no $\S 3^{\circ}$ do Art. $5^{\circ}$ da CF. Assim se ficasse configurado essa hipótese, o tribunal iria ter que se pronunciar sobre qual norma prevaleceria, já que ambas possuem o mesmo nível hierárquico.

Mesmo assim, essa realização do controle de convencionalidade ficaria prejudicada na prática judicial brasileira pelo entendimento da suprema corte que concebe que os tratados não incorporados pelo rito especial, teriam hierarquia supralegal (devendo obediência as normas constitucionais, sejam elas originárias ou provenientes de emendas constitucionais). 
Isso inviabiliza consideravelmente o controle interno de convencionalidade das Emendas Constitucionais, pois até o presente momento apenas dois instrumentos internacionais de direitos humanos foram incorporados pela sistemática especial: a Convenção sobre os Direitos das Pessoas com Deficiência e seu Protocolo Facultativo (Decreto Legislativo 186/2008 e Decreto 6.949/2009). Desse modo, seguindo a jurisprudência atual do STF, apenas esses dois tratados poderiam controlar a convencionalidade de uma Emenda Constitucional, o que é bastante incipiente.

Podem também ser objeto do controle de convencionalidade: a) regras internas de caráter legislativo, administrativo ou de qualquer outro caráter; b) práticas estatais de qualquer dos três poderes (HITTERS, 2009) e c) a jurisprudência da Corte Suprema ou Tribunal Constitucional, quando a mesma tem efeito vinculante para os tribunais inferiores (SAGUÉS, 2010).

2.6 Normas que servem de parâmetro para o controle de convencionalidade

É pertinente também apontar qual é o material normativo que será utilizado para determinar se as normas internas são ou não inconvencionais. Podem servir de normas parâmetros para a realização do controle interno de convencionalidade, todos os tratados internacionais de direitos humanos incorporados e em vigor no ordenamento brasileiro.

A distinção que é feita diz respeito ao controle interno difuso ou concentrado, já que no difuso todos os tratados de direitos humanos servirão de normas parâmetro, enquanto no controle concentrado apenas os tratados de direitos humanos que tenham sido integrados ao direito brasileiro obedecendo a sistemática prevista no $\S 3^{\circ}$ do Art. $5^{\circ}$ da CF. É importante lembrar que segundo a jurisprudência da Corte Interamericana de Direitos Humanos analisada no tópico 2.2 desse trabalho, nesse exercício os juízes nacionais devem considerar não apenas o texto do tratado internacional, mas também a intepretação realizada pela Corte Interamericana.

No que tange ao controle externo de convencionalidade, o material para realizar a comparação e efetivar o controle de convencionalidade, não se limita a Convenção Americana de Direitos Humanos, podendo abranger outros tratados internacionais que integram o conjunto jurídico básico em matéria de proteção dos direitos humanos, abarcando as convenções internacionais sobre as quais a Corte exerce sua competência material (BAZAN, 2015). 
A doutrina utiliza a expressão corpus iuris interamericano para caracterizar esses instrumentos de proteção regional de direitos humanos que além da Convenção Americana, pode incluir exemplificadamente: o Protocolo de San Salvador em matéria de direitos econômicos, sociais e culturais; o Protocolo relativo a abolição da pena de morte; a Convenção para prevenir e sancionar a tortura; a Convenção de Belém do Pará para erradicação da violência contra a mulher e a Convenção sobre desaparecimento forçado de pessoas (BAZAN, 2015; HITTERS, 2009).

\subsection{Efeitos do controle de convencionalidade}

O objetivo do controle de convencionalidade é definir se a norma interna é convencional ou não. Se for, o juiz aplica e caso ela seja inconvencional ela não poderá ser aplicada. A norma inconvencional é considerada inválida, carecendo de efeitos desde a sua edição, portanto, a declaração geraria efeitos retroativos ou ex tunc (SAGUÉS, 2010).

Esse efeito de eliminar as normas inconvencionais locais pode ser chamado de efeito destrutivo. Porém outro efeito pode ser reconhecido, o efeito construtivo, que possui uma certa semelhança com o princípio da interpretação conforme à Constituição. Desse modo, não obrigatoriamente deveriam ser consideradas inválidas as normas internas inconvencionais, mas também poderiam ser, na medida do possível, interpretadas em conformidade com o tratado internacional (SAGUÉS, 2010).

O efeito construtivo possibilita que caso a norma tenha mais de interpretação possível, o operador deve optar aquela que coincida e não contrarie o tratado internacional, permitindo, dessa forma, que as normas internas permaneçam válidas, desde que na sua aplicação se escolha a interpretação que esteja de acordo com o instrumento internacional (SAGUÉS, 2010).

No controle difuso interno de convencionalidade, em regra, a decisão terá efeitos $e x$ tunc e inter partes. Já no controle concentrado interno de convencionalidade, a decisão terá como regra, efeitos erga omnes, ex tunc e vinculante (MARTINS; MOREIRA, 2011).

Já em relação ao controle externo de convencionalidade, preliminarmente, os efeitos das sentenças da Corte Interamericana de Direitos Humanos seriam inter partes, em razão do que dispõe o Art. 68.1 da Convenção Americana de Direitos Humanos ${ }^{15}$. A dúvida é em

15 “Os Estados Partes na Convenção comprometem-se a cumprir a decisão da Corte em todo caso em que forem partes". 
relação a possibilidade da sentença da Corte gerar efeitos erga omnes, atingindo países que não participaram do julgamento.

É importante apontar que a doutrina reconhece que as sentenças da Corte podem apresentar os efeitos dos seus julgamentos em duas dimensões: a) dimensão subjetiva e direta para as partes envolvidas no conflito internacional; b) dimensão objetiva e indireta para os Estados que não participaram da controvérsia. A primeira dimensão gera efeitos inter partes, que representa o dever do Estado em cumprir o estabelecido na sentença da Corte, de forma integral, plena e efetiva. Já a dimensão objetiva produz efeitos erga omnes, alcançando todos os Estados Partes da Convenção Americana, pois todas as autoridades internas ficam submetidas a efetividade convencional e, portanto, ao parâmetro interpretativo estabelecido pela Corte Interamericana, como padrão mínimo de efetividade da norma convencional, derivada da obrigação estatal de respeito, garantia e adequação reconhecidos pelos Arts.1.1 e 2 do Pacto de San José (MAC-GREGOR, 2013).

Um exemplo para ilustrar esses efeitos distintos: Quando a Corte Interamericana estabelece que o Estado repare a vítima da violação de direitos humanos (Ex.: pagamento de indenizações, revogar ou elaborar leis, processar e se for caso punir os responsáveis etc), tal efeito deve ser observado apenas pelo Estado que foi condenado no julgamento. Já quando a Corte entende, por exemplo, na motivação das suas decisões que as leis de anistia são incompatíveis com o Pacto de San José ou que o crime de desacato viola a liberdade de expressão, tal entendimento interpretativo deve ser observado por todos os países que fazem parte do Sistema Interamericano de Proteção de Direitos Humanos.

Dessa forma, quando uma sentença interamericana envolvendo a responsabilidade internacional de um determinado Estado, esse julgamento produz eficácia vinculante direta, completa e absoluta perante as autoridades domésticas de cumprir com a determinação judicial. Diferentemente para os Estados que não foram partes na demanda, a vinculação limita-se a jurisprudência interamericana, ou seja, a norma convencional interpretada. Esse efeito interpretativo é relativo, na medida que se produz quando não haja uma interpretação que conceda maior efetividade ao tratado no âmbito interno, já que as autoridades nacionais podem aumentar o padrão interpretativo mínimo (MAC-GREGOR, 2013).

Um argumento apontado para o reconhecimento dessa vinculação indireta está no Art. 69 da Convenção Americana, na parte que o mesmo estabelece a obrigatoriedade das sentenças da Corte serem comunicadas aos demais Estados-Partes da Convenção. Se tal vinculação não existisse, o dispositivo ficaria sem sentido (BAZAN, 2015). 


\section{BREVE ANÁLISE DO CRIME DE DESACATO}

O crime de desacato encontra-se previsto no Art. 331 do Código Penal ${ }^{16}$. Pretende-se apresentar alguns esclarecimentos gerais desse ilícito antes de adentrar no julgamento do STJ que analisou a sua inconvencionalidade.

Do ponto de vista histórico, a doutrina registra que o crime de desacato já era aplicado na época do Direito Romano, remontando ao período da Antiguidade Clássica. Em relação ao direito brasileiro, o primeiro diploma legislativo a usar expressamente a nomenclatura desacato foi o Código Penal de 1890 (BITENCOURT, 2010).

Considera-se que o funcionário público é um representante da Administração Pública e na sua atuação funcional pode praticar atos desagradáveis, mesmo que realizadas para alcançar o interesse público. Ou então, a só constatação do funcionário representar os interesses estatais, pode fazer com que algumas pessoas atuem de forma desrespeitosa em relação as funções que são exercidas pelo funcionário (GRECO, 2015).

O bem jurídico protegido pelo tipo penal consiste em garantir o regular desempenho da Administração Pública e o reconhecimento que o funcionário público deve ter perante a sociedade (PRADO, 2011). Tutela-se especialmente a moralidade e a probidade administrativa, almejando com isso que as ordens emitidas pelos funcionários públicos sejam cumpridas (BITENCOURT, 2010).

O objeto da tipificação penal está no verbo desacatar, ou seja, "desrespeitar, ofender, menosprezar funcionário público no exercício da função ou em razão dela" (BITENCOURT, 2010, p. 211). Desse modo a conduta consiste numa atitude de desrespeito, aversão, repulsa, indignação, tendo a finalidade de ofender e humilhar o funcionário público (PRADO, 2011) e por isso mesmo, para que o delito se configure é necessária a presença do dolo específico que consiste na vontade deliberada do sujeito ativo em menosprezar a função pública desempenhada pelo ofendido (BITENCOURT, 2010).

O problema que se percebe no crime de desacato é que o tipo penal apresenta uma redação bastante aberta, podendo alcançar diversos tipos de conduta, sendo difícil diferenciar se seria um simples descontentamento ou não (GOMES; GONÇALVES, 2016). Outro problema percebido na prática de diversas repartições públicas brasileiras é que em muitas

\footnotetext{
16 "Desacatar funcionário público no exercício da função ou em razão dela: Pena - detenção, de 6 (seis) meses a 2 (dois) anos, ou multa".
} 
delas existem cartazes contendo a redação do Art. 331 do Código Penal, atitude essa que pode inibir o cidadão de efetuar suas queixas contra a prestação dos serviços.

Também certas condutas abusivas de alguns funcionários públicos acabam trazendo muita desconfiança por parte da população para a criminalização do desacato. A famosa expressão "você sabe com quem está falando" é um exemplo de conduta que muitas vezes acaba amedrontando ou afastando a fiscalização da atividade administrativa. Um caso emblemático que ganhou repercussão nacional foi o da agente de trânsito do Rio de Janeiro Luciana Tamburi, que foi condenada a pagar uma indenização para um juiz que foi parado numa blitz policial e que dirigia sem habilitação e um veículo sem placas. O juiz tentou ter um tratamento distinto em razão de seu cargo e deu voz de prisão em flagrante para a agente de trânsito por desacato pelo fato da mesma ter dito que juiz não é Deus.

A doutrina penalista brasileira considera que o cidadão tem o direito de efetuar críticas contra a atuação dos agentes públicos e que não se configura desacato a conduta de reclamar contra o desempenho funcional de alguém. Assegura-se, dessa forma, o direito de fiscalização por parte dos cidadãos permitindo que haja reclamações relativamente aos serviços públicos que são prestados, desde que não tenha o propósito de ofender ou injuriar (BITENCOURT, 2010; PRADO, 2011; NUCCI, 2014).

Diante do exposto, observa-se que o crime de desacato pode configurar uma possível violação ao princípio da liberdade de pensamento e de expressão, previsto no Art. 13 da Convenção Americana de Direitos Humanos ${ }^{17}$. Foi justamente sobre esse assunto que o Superior Tribunal de Justiça teve a oportunidade de se pronunciar no julgamento do REsp 1.640.084, assunto que será abordado no próximo tópico.

\section{A TEORIA NA PRÁTICA: A INCONVENCIONALIDADE DO CRIME DE DESACATO E O RESP 1.640.084}

\footnotetext{
17 “ 1 . Toda pessoa tem direito à liberdade de pensamento e de expressão. Esse direito compreende a liberdade de buscar, receber e difundir informações e idéias de toda natureza, sem consideração de fronteiras, verbalmente ou por escrito, ou em forma impressa ou artística, ou por qualquer outro processo de sua escolha. 2. O exercício do direito previsto no inciso precedente não pode estar sujeito a censura prévia, mas a responsabilidades ulteriores, que devem ser expressamente fixadas pela lei e ser necessárias para assegurar: a. o respeito aos direitos ou à reputação das demais pessoas; ou b. a proteção da segurança nacional, da ordem pública, ou da saúde ou da moral públicas. 3. Não se pode restringir o direito de expressão por vias ou meios indiretos, tais como o abuso de controles oficiais ou particulares de papel de imprensa, de frequiências radioelétricas ou de equipamentos e aparelhos usados na difusão de informação, nem por quaisquer outros meios destinados a obstar a comunicação e a circulação de idéias e opiniões. 4. A lei pode submeter os espetáculos públicos a censura prévia, com o objetivo exclusivo de regular o acesso a eles, para proteção moral da infância e da adolescência, sem prejuízo do disposto no inciso 2. 5. A lei deve proibir toda propaganda a favor da guerra, bem como toda apologia ao ódio nacional, racial ou religioso que constitua incitação à discriminação, à hostilidade, ao crime ou à violência".
} 
A análise do presente julgamento se torna relevante haja vista de se tratar do pronunciamento de um tribunal superior brasileiro sobre a teoria do controle de convencionalidade (fato escasso no Brasil), o que traz a oportunidade de averiguar como esse referencial teórico vem sido incorporado na prática judicial do Brasil.

Já havia registro anterior de decisões que haviam analisado a inconvencionalidade do desacato, mas nenhuma com a amplitude do STJ, que exerce sua jurisdição em todo o país e que influencia a decisão de diversos magistrados no território nacional.

O julgamento foi proferido em 15 de dezembro de 2016, pela Quinta Turma do STJ e teve como relator o Min. Marcelo Navarro Ribeiro Dantas. Por unanimidade e seguindo o voto do relator, os Ministros que compõe a turma entenderam que crime de desacato viola o Art. 13 da Convenção Americana de Direitos Humanos, conforme pode se constatar na ementa do julgado, transcrita abaixo:

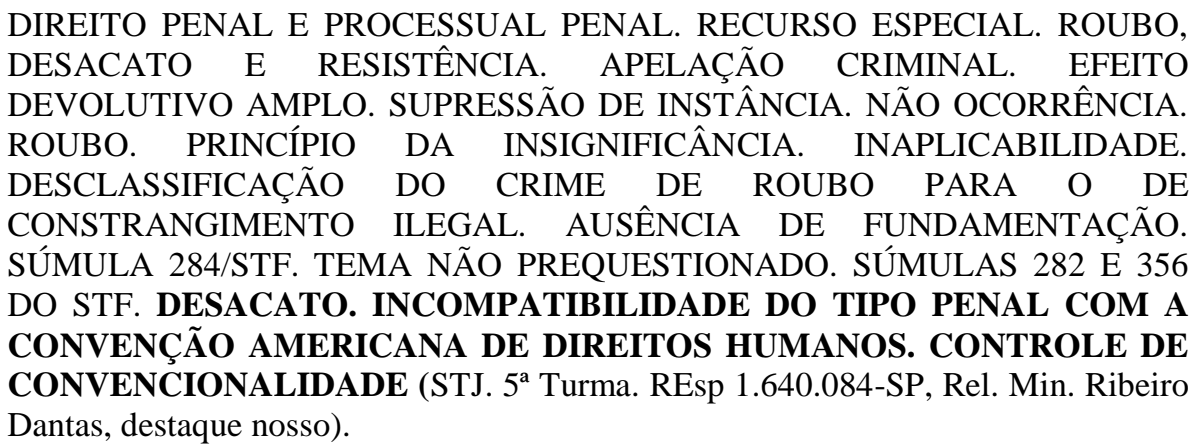

Para esclarecer, no caso concreto uma determinada pessoa foi condenada por diversos crimes, entre eles o desacato. Contra a decisão de primeira instancia, interpôs-se um recurso perante o TJSP que manteve a condenação pelo crime de desacato e posteriormente houve a impetração do Recurso Especial perante o STJ.

O TJSP entendeu que o desacato não configurava violação ao Pacto de San José da Costa Rica. O Recurso Especial perante o STJ foi impetrado com fundamentação no Art. 105, III, a da Constituição Federal ${ }^{18}$. Com base nesse dispositivo, o STJ pode se pronunciar sobre a validade dos tratados internacionais, no julgamento de um Recurso Especial, quando a decisão proferida pelas instâncias inferiores, tenham prejudicado a aplicação do instrumento internacional (MAZZUOLI; BICHARA, 2017).

\footnotetext{
18 “Compete ao Superior Tribunal de Justiça: III - julgar, em recurso especial, as causas decididas, em única ou última instância, pelos Tribunais Regionais Federais ou pelos tribunais dos Estados, do Distrito Federal e Territórios, quando a decisão recorrida: a) contrariar tratado ou lei federal, ou negar-lhes vigência".
} 
Foi justamente o que ocorreu no presente julgamento. No voto do relator, alguns aspectos relacionados a aplicação do controle de convencionalidade merecem destaque: a) menção a doutrina de Valério Mazzuoli; b menção a sentenças da Corte Interamericana de Direitos Humanos (Casos Almonacid Arellano, Palamara Iribarne e Loayza Tamayo); c) menção a dispositivos da Convenção Americana de Direitos Humanos (Arts. 2, 13 e 29).

Quanto aos pontos enfatizados nas letras "b" e "c", o relator acaba seguindo ao entendimento da Corte Interamericana, já mencionado nesse trabalho, que no exercício do controle de convencionalidade os juízes domésticos devem levar em consideração além das previsões da Convenção Americana, a jurisprudência da Corte.

A importância dessa preocupação do relator percebe-se na citação ao caso Palamara Iribane, onde justamente houve a questão da aplicação do crime de desacato no Chile, levando a Corte a concluir pela sua incompatibilidade com o Art. 13 do Pacto de San José da Costa Rica (GOMES; GONÇALVES, 2016). O Tribunal entendeu nesse julgamento que:

\begin{abstract}
As leis de desacato aplicadas a Palamara Iribarne estabeleceram sanções desproporcionais por realizar críticas ao funcionamento das instituições do Estado e seus membros, removendo o debate essencial para o funcionamento de um sistema verdadeiramente democrático e restringindo desnecessariamente o direito à liberdade de pensamento e expressão (CORTE INTERAMERICANA DE DIREITOS HUMANOS. Caso Palamara Iribane Vs. Chile, $§ 88$, tradução nossa). ${ }^{19}$
\end{abstract}

Outro ponto importante do Caso Palamara Iribane, foi a consideração da Corte que a inclusão no ordenamento jurídico chileno de normas de desacato contrariando o Art. 13 da Convenção, algumas das quais ainda estavam em vigor, seria também uma violação ao Art. $2^{\circ}$ do Pacto de San José da Costa Rica (CORTE INTERAMERICANA DE DIREITOS HUMANOS. Caso Palamara Iribane Vs. Chile, § 95).

No seu voto, o relator entendeu que a descriminalização do desacato não impede eventual responsabilização civil ou criminal (Ex.: calúnia, injúria, difamação), por eventuais abusos nas manifestações perante os funcionários públicos. Entendeu também a ocorrência de violação do princípio da isonomia, por tratar distintamente os funcionários públicos dos particulares.

No final foi dado provimento parcial ao Recurso Especial, afastando-se a condenação pelo crime de desacato, em razão da hierarquia supralegal dos tratados de direitos humanos e de sua eficácia paralisante, tornado o dispositivo do Código Penal inválido.

\footnotetext{
19 No original: "La Corte considera que la legislación sobre desacato aplicada al señor Palamara Iribarne establecía sanciones desproporcionadas por realizar críticas sobre el funcionamiento de las instituciones estatales y sus miembros, suprimiendo el debate esencial para el funcionamiento de un sistema verdadeiramente democrático y restringiendo innecesariamente el derecho a la libertad de pensamiento y de expresión".
} 


\section{CONSIDERAÇÕES FINAIS}

Paulatinamente a teoria do controle de convencionalidade vem ganhado espaço no Brasil, tanto na doutrina quanto na jurisprudência. A decisão do STJ acima analisada demonstra uma abertura para a aplicação do Direito Internacional dos Direitos Humanos, refletindo o dever de realização pelos juízes brasileiros do controle de convencionalidade.

Em razão da pluralidade de ordens jurídicas presenciada no nosso sistema constitucional, o ordenamento jurídico brasileiro se abre para a incidência de normas internacionais de proteção ao ser humano, gerando o desafio para a compatibilização entres essas e as normas internas. $\mathrm{O}$ exercício do controle de convencionalidade permite essa compatibilização, possibilitando um diálogo entre ambas as fontes normativas, com a finalidade de aplicar aquela que melhor tutele os direitos humanos fundamentais (princípio pro homine).

Para analisar como os juízes brasileiros estão desempenhando essa missão de controlar a convencionalidade da lei, foi escolhido o caso do crime do desacato e sua compatibilidade com a Convenção Americana de Direitos Humanos, especialmente a liberdade de expressão consagrada no Art. 13 da mesma.

Como foi ressaltado no trabalho, há entendimento doutrinário e jurisprudencial defendendo que as sentenças da Corte Interamericana tenham efeitos erga omnes. Apesar de não ter mencionado esse entendimento em seu voto, é positivo o fato do Min. Marcelo Navarro ter mencionado em sua fundamentação o Caso Palamara Iribane, tendo em conta que nesse julgamento a Corte Interamericana teve a oportunidade de se pronunciar sobre a compatibilidade das leis de desacato existentes no Chile com o Pacto de San José da Costa Rica.

Com o uso mais frequente do controle de convencionalidade, os operadores do direito irão perceber que os direitos humanos fundamentais possuem uma dupla proteção, tanto a nível local como no plano internacional. Nessa proteção, ambos os níveis podem e devem ser utilizados para proporcionar uma maior efetividade de direitos tão importantes para o ser humano, não sendo preciso esperar uma manifestação de um órgão internacional para tutelar esses direitos.

O dever dos magistrados brasileiros de exercerem a averiguação de convencionalidade vai gerar para os mesmos uma atualização maior em suas atribuições, pois devem se 
preocupar não apenas com o entendimento dos tribunais brasileiros, mas também começar a compreender o funcionamento e a interpretação de organismos internacionais que podem atuar na proteção dos direitos humanos.

A questão da inconvencionalidade do desacato ainda não ganhou uma resolução definitiva. Isso em razão do mesmo STJ, em julgamento proferido em 24 de maio de 2017, ter entendido pela continuidade do crime de desacato (HC 379.269). Portanto, até que haja um entendimento do STF, revogação legislativa do tipo penal de desacato ou algum caso perante o sistema interamericano onde o Brasil seja parte, a aplicação do crime de desacato continuará sendo um problema a ser enfrentado.

\section{REFERÊNCIAS}

BAZÁN, Victor. O Controle de Convencionalidade e a Necessidade de Intensificar um Adequado Diálogo Jurisprudencial. Direito Público, [S.1.], v. 8, n. 41, jan. 2013. ISSN 2236$1766 . \quad$ Disponível em: <https://www.portaldeperiodicos.idp.edu.br/direitopublico/article/view/1953>. Acesso em: 28 jun. 2017.

. El control de convencionalidad como instrumento para proteger derechos esenciales y prevenir la responsabilidad internacional del Estado. Anuario Iberoamericano de Justicia Constitucional, [S.1.], n. 19, p. 25-70, nov. 2015. ISSN 1989-5585. Disponível em: <https://recyt.fecyt.es/index.php/AIJC/article/view/42043>. Acesso em: 28 jun. 2017.

BITENCOURT, Cezar Roberto. Tratado de direito penal: dos crimes contra a administração pública e dos crimes praticados por prefeitos. 4. ed. São Paulo: Saraiva, 2010. v. 5.

BRASIL. Constituição da República Federativa do Brasil de 1988. Disponível em: <http://www.planalto.gov.br/ccivil_03/constituicao/ConstituicaoCompilado.htm>. Acesso em: 28 jun. 2017

Decreto $n^{\circ} 7.030$, de 14 de dezembro de 2009. Promulga a Convenção de Viena sobre o Direito dos Tratados, concluída em 23 de maio de 1969, com reserva aos Artigos 25 e 66. Disponível em: <http://www.planalto.gov.br/ccivil_03/_ato20072010/2009/decreto/d7030.htm>. Acesso em: 28 jun. 2017.

Decreto $n^{\circ} 678$, de 06 de novembro de 1992. Promulga a Convenção Americana sobre Direitos Humanos (Pacto de São José da Costa Rica), de 22 de novembro de 1969. Disponível em: 〈http://www.planalto.gov.br/ccivil_03/decreto/d0678.htm>. Acesso em: 28 jun. 2017. 
. Decreto-Lei $\mathrm{n}^{\circ}$ 2.848, de 07 de dezembro de 1940. Código Penal. Disponível em: <http://www.planalto.gov.br/ccivil_03/decreto-lei/Del2848compilado.htm>. Acesso em: 28 jun. 2017.

- Supremo Tribunal Federal. Recurso Extraordinário no 466.343/SP, 03 de dezembro de 2008. Relator Min. Cezar Peluso. Disponível em:< http://redir.stf.jus.br/paginadorpub/paginador.jsp?docTP=AC\&docID=595444>. Acesso em: 28 jun. 2017.

. Superior Tribunal de Justiça. Recurso Especial 1640084/SP, 15 de dezembro de 2016.
Relator
Min.
Ribeiro
Dantas.
Disponível
em:
<http://www.stj.jus.br/static_files/STJ/Midias/arquivos/Noticias/RECURSO\%20ESPECIAL \%20N\%C2\%BA\%201640084.pdf>. Acesso em: 28 jun. 2017.

CAVALLO, Gonzalo Aguilar. El control de convencionalidad: análisis en derecho comparado. Rev. direito GV, São Paulo, v. 9, n. 2, p. 721-754, Dec. 2013. Disponível em: < http://direitosp.fgv.br/publicacoes/revista/artigo/el-control-de-convencionalidad-analisis-enderecho-comparado>. Acesso em: 28 jun. 2017.

CHAVES, Denisson Gonçalves; SOUSA, Mônica Teresa Costa. O controle de convencionalidade e a autoanálise do poder judiciário brasileiro. Revista da Faculdade de Direito UFPR, Curitiba, PR, Brasil, v. 61, n. 1, p. 87 - 113, abr. 2016. ISSN 2236-7284. Disponível em: <http://revistas.ufpr.br/direito/article/view/43787>. Acesso em: 28 jun. 2017.

CORTE INTERAMERICANA DE DIREITOS HUMANOS. Caso Almonacid Arellano e outros Vs. Chile. Exceções Preliminares, Mérito, Reparações e Custas. Sentença de 26 de setembro de 2006. Disponível em: <http://www.cnj.jus.br/files/conteudo/arquivo/2016/04/7172fb59c130058bc5a96931e41d04e2 .pdf>. Acesso em: 28 jun. 2017.

Disponível

Caso Gelman Vs. Uruguai. Mérito e Reparações. Sentença de 24 de fevereiro de 2011. <http://www.cnj.jus.br/files/conteudo/arquivo/2016/04/09b4d396111fe41e886a744a9f8753e1 .pdf>. Acesso em: 28 jun. 2017.

Caso Gomes Lund e outros Vs. Brasil. Exceções Preliminares, Mérito, Reparações e Custas. Sentença de 20 de novembro de 2010. Disponível em: <http://www.corteidh.or.cr/docs/casos/articulos/seriec_219_por.pdf>. Acesso em: 28 jun. 2017. 
. Caso "A Última Tentação de Cristo" (Olmedo Bustos e outros) Vs. Chile. Mérito, Reparações e Custas. Sentença de 05 de fevereiro de 2001. Disponível em: <http://www.cnj.jus.br/files/conteudo/arquivo/2016/04/f30eb7942e6ea89e4d2ec4ca870784d3. pdf>. Acesso em: 28 jun. 2017.

Caso Cabrera García y Montiel Flores vs. México. Excepción Preliminar, Fondo, Reparaciones y Costas. Sentença de 26 de novembro de 2010. Disponível em: $<$ http://www.corteidh.or.cr/docs/casos/articulos/seriec_220_esp.pdf>. Acesso em: 28 jun. 2017.

Caso Palamara Iribarne Vs. Chile. Fondo, Reparaciones y Costas. Sentença de 22 de novembro de 2005. Disponível em: <http://www.corteidh.or.cr/docs/casos/articulos/seriec_135_esp.pdf >. Acesso em: 28 jun. 2017.

Caso Trabajadores Cesados del Congreso (Aguado Alfaro y otros) Vs. Perú. Excepciones Preliminares, Fondo, Reparaciones y Costas. Sentença de 24 de novembro de 2006. Disponível em: 〈http://www.corteidh.or.cr/docs/casos/articulos/seriec_158_esp.pdf>. Acesso em: 28 jun. 2017.

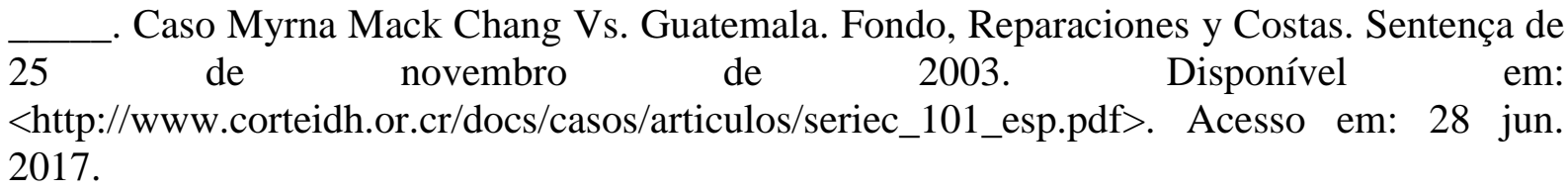

GARCIA, Hernán Alejandro Olano. Teoría del control de convencionalidad. Estudios constitucionales, Santiago, v. 14, n. 1, p. 61-94, jul. 2016. Disponível em $<$ http://www.scielo.cl/scielo.php?script=sci_arttext\&pid=S0718-

$52002016000100003 \& \operatorname{lng}=$ es\&nrm=iso>. Acesso em: 28 jun. 2017.

GOMES, Eduardo Biacchi; GONÇALVES, Ane Elise Brandalise. O controle de convencionalidade, a Convenção Americana de Direitos Humanos e o crime de desacato. Revista Jurídica da Presidência, Brasília, v. 18, n. 114, Fev./Maio 2016, p. 73-96. Disponével em

https://revistajuridica.presidencia.gov.br/index.php/saj/article/view/1207/1142>. Acesso em: 28 jun. 17.

GONÇALVES, Vinicius de Almeida. A figura do bloco de convencionalidade nas decisões proferidas pela corte interamericana de direitos humanos. Revista Eletrônica do Curso de Direito da UFSM, Santa Maria, RS, v. 8, n. 2, p. 398-425, dez. 2013. ISSN 1981-3694. Disponível em: <https://periodicos.ufsm.br/revistadireito/article/view/10793〉. Acesso em: 28 jun. 2017. 
GRECO, Rogério. Curso de direito penal: Arts. 250 ao 361 do código penal. 11. ed. Niterói: Impetus, 2015. v. 4.

HITTERS, Juan Carlos. Control de constitucionalidad y control de convencionalidad. Comparación (Criterios fijados por la Corte Interamericana de Derechos Humanos). Estudios constitucionales, Santiago, v. 7, n. 2, p. 109-128, 2009. Disponível em: $<$ http://www.scielo.cl/scielo.php?script=sci_arttext\&pid=S071852002009000200005\&lng=es\&nrm=iso>. Acesso em: 28 jun. 2017.

MAC-GREGOR, Eduardo Ferrer. Interpretación conforme y control difuso de convencionalidad: El nuevo paradigma para el juez mexicano. Estudios constitucionales, Santiago, v. 9, n. 2, p. 531-622, 2011. Disponível em: <http://www.scielo.cl/scielo.php?script=sci_arttext\&pid=S071852002011000200014\&lng=es\&nrm=iso>. Acesso em: 28 jun. 2017.

Eficacia de la sentencia interamericana y la cosa juzgada internacional: vinculación directa hacia las partes (res judicata) e indirecta hacia los estados parte de la convención americana (res interpretata) (sobre el cumplimiento del caso gelman vs. Uruguay). Estudios constitucionales, Santiago, v. 11, n. 2, p. 641-694, 2013. Disponível em: $<$ http://www.scielo.cl/scielo.php?script=sci_arttext\&pid=S0718-

52002013000200017\&lng=es\&nrm=iso>. Acesso em: 28 jun. 2017.

MARTINS, Leonardo; MOREIRA, Thiago Oliveira. Constitucionalidade e Convencionalidade de Atos do Poder Público: concorrência ou hierarquia? Um contributo em face da situação jurídico constitucional brasileira. Anuario de Derecho Constitucional Latino Americano. Año XVII, Montevideo, 2011, p. 463-483. Disponível em: <http://www.kas.de/wf/doc/kas_28960-1522-4-30.pdf?111201194716>. Acesso em: 28 jun. 2017.

MAZZUOLI, Valério de Oliveira. O controle jurisdicional da convencionalidade das leis. 2. ed. São Paulo: Revista dos Tribunais, 2011.

; BICHARA, Jahyr-Philippe. O judiciário brasileiro e o direito internacional: análise crítica da jurisprudência nacional. Belo Horizonte: Arraes, 2017.

NUCCI, Guilherme de Souza. Código penal comentado. 15. ed. Rio de Janeiro: Forense, 2015.

PIOVESAN, Flávia. Direitos Humanos e o Direito Constitucional Internacional. 14. ed. São Paulo: Saraiva, 2013. 
PRADO, Luiz Regis. Curso de direito penal brasileiro: Parte especial - Arts. 250 a 359-H. 7.ed. São Paulo: Revista dos Tribunais, 2011. v. 3.

RAMIREZ, Sergio Garcia. El control judicial interno de convencionalidad. Rev. IUS, Puebla , v. 5, n. 28, p. 123-159, dic. 2011. Disponível em $<$ http://www.scielo.org.mx/scielo.php?script=sci_arttext\&pid=S1870-

$21472011000200007 \& \operatorname{lng}=e s \& n r m=$ iso $>$. Acesso em: 28 jun. 2017.

; SÁNCHES, Julieta Morales. El Control de Convencionalidad: Construcciones y dilemas. In: CRUZ, Gerardo Eto (coord): Treinta años de jurisdicción constitucional en el Perú. Tomo II. Lima: Centro de Estudios Constitucionais, 2014. Disponível em: <http://www.tc.gob.pe/tc/private/adjuntos/cec/publicaciones/publicacion/libro_30_anos_tomo 2.pdf>. Acesso em: 28 jun. 2017.

RAMOS, André de Carvalho. Pluralidade das ordens jurídicas: uma nova perspectiva na relação entre o Direito Internacional e o Direito Constitucional. Revista da Faculdade de Direito, Universidade de São Paulo, São Paulo, p. 497-524, jan. 2012. ISSN 2318-8235. Disponível em: <http://www.revistas.usp.br/rfdusp/article/view/67955>. Acesso em: 28 jun. 2017.

Curso de direitos humanos. São Paulo: Saraiva, 2014.

ROJAS, Claudio Nash. Control de convencionalidad. Precisiones conceptuales y desafíos a la luz de la jurisprudencia de la Corte Interamericana de Derechos Humanos. Anuario de Derecho Constitucional Latinoamericano, Año XIX, Bogotá, 2013, p. 489-509, ISSN 2346-0849. Disponível em: <http://www.kas.de/wf/doc/kas_36055-1522-430.pdf?131113170353>. Acesso em: 28 jun. 2017

SAGUES, Néstor Pedro. Obligaciones internacionales y control de convencionalidad. Estudios constitucionales, Santiago, v. 8, n. 1, p. 117-136, 2010. Disponível em: <http://www.scielo.cl/scielo.php?script=sci_arttext\&pid=S071852002010000100005\&lng=es\&nrm=iso>. Acesso em:28 jun. 2017.

TORELLY, Marcelo. Controle de Convencionalidade: constitucionalismo regional dos direitos humanos? Revista Direito e Práxis, Rio de Janeiro, vol.8, $\mathrm{n}^{\circ}$ 1, mar. 2017. Disponível em: $<$ http://www.epublicacoes.uerj.br/index.php/revistaceaju/article/view/23006>. Acesso em: 28 Jun. 2017. 


\begin{abstract}
The theory of conventionality control has brought important debates in Brazilian law. One of the discussions concerns the adequacy of the crime of contempt with the American Convention on Human Rights. The Inter-American Court of Human Rights has already ruled on the incompatibility of the criminal type and freedom of expression provided for in the Pact of San José of Costa Rica. In the case of Brazil, our criminal legislation contemplates such an offense, arising the importance of knowing how the Brazilian Judiciary will act when having to judge concrete cases where the unconventionality of the offense is raised.
\end{abstract}

Keywords: Contempt. Conventionality Control. Judicial Branch. 